\title{
Reflexões sobre a humanização do cuidado na presença de uma doença ameaçadora da vida
}

\author{
Tamara Borox Guimarães* \\ Cristiana Magni**
}

\begin{abstract}
Resumo
A pesquisa de cunho qualitativa foi realizada a partir do relato oral de uma profissional da Enfermagem que vivenciou o diagnóstico e tratamento de uma doença ameaçadora da vida, tendo como objetivo descrever reflexões sobre a humanização do cuidado na atuação profissional com a terminalidade da vida. Os profissionais da área da saúde convivem em suas práticas com o enfrentamento de doenças ameaçadoras da vida e vivenciam o impacto e as mudanças que o diagnóstico e tratamento causam na vida de pacientes e familiares. A análise do conteúdo do relato da profissional de saúde ampliou a reflexão sobre a multidimensionalidade do ser humano no processo saúde-doença, devendo ser considerada primordialmente no âmbito da corresponsabilização da equipe multidisciplinar para a oferta de um cuidado humanizado a pacientes e familiares. A habilidade de comunicação efetiva dos profissionais para com os pacientes e familiares ressalta a importância da capacitação para uma assistência centrada nas necessidades do paciente. A espiritualidade, a partir do sofrimento vivenciado no processo de adoecimento, surge como uma fonte de apoio para a aceitação da doença. Essas reflexões despertam a necessidade de a atuação profissional ser baseada no cuidado humanizado frente ao processo de morte e morrer e uma ferramenta para alcançar esse objetivo pode ser a construção de espaços para reflexões e educação constante dos profissionais de saúde.
\end{abstract}

Palavras-chave: profissionais da saúde, assistência centrada no paciente, humanização, cuidado.

\section{Reflections on the humanization of care in the presence of a life-threatening disease}

\begin{abstract}
The qualitative research was carried out based on the oral report of a Nursing professional experienced the diagnosis and treatment of a life threatening disease, with the objective of describing reflections on the humanization of care in professional performance with the terminality of life. Health care professionals live in their practices to face life-threatening diseases and experience the impact and changes that diagnosis and treatment cause in the lives of patients and family members. Content's analysis of health professional's report expanded the reflection on the multidimensionality of the human being in the health-disease process, and should be considered primarily in the context of the co-responsibility of the multidisciplinary team for offering humanized care to patients and family members. The professional's ability to communicate effectively with patients and family members underscores the importance of training for assistance centered on the needs of the patient. Spirituality, from the suffering experienced in the illness process, appears as a source of support for the acceptance of the disease. These reflections arouse the need for professional performance to be based on humanized care in the face of the process of death and dying and a tool to achieve this goal can be the construction of spaces for reflection and constant education of health professionals. Keywords: health professionals, patient-centered care, humanization, care.
\end{abstract}

* Fonoaudióloga pela Universidade Estadual Centro Oeste - UNICENTRO e Mestranda pelo PPG Interdisciplinar em Desenvolvimento Comunitário. ** Doutora em Ciências Biológicas pela UFP, Mestre em Educação pela PUCSP e Docente da UNICENTRO no PPG Interdisciplinar em Desenvolvimento Comunitário. 


\section{Introdução}

O aumento da expectativa de vida vem crescendo na população brasileira, simultaneamente com o número elevado de doenças crônicas, como o câncer (Sanches, Rabin \& Teixeira, 2018). Segundo registros da Organização Mundial da Saúde (WHO, 2002), o Brasil assiste a um milhão de óbitos por ano, sendo 650 mil decorrentes de doenças crônicas e cerca de 70\% dessas mortes ocorrem de forma institucionalizada em hospitais em maior quantidade nas unidades de terapia intensiva.

O processo de adoecimento causa mudanças significativas na vida dos pacientes e familiares e, com isso, faz-se necessário que o cuidado prestado seja voltado para o controle de sintomas e melhora na qualidade de vida durante o processo de enfrentamento da doença (Azevedo, Tommaso, Burlá, Santos, Dias \& Py, 2015).

Os cuidados paliativos são considerados como uma forma de assistência para pacientes que apresentem diagnóstico de doenças ameaçadoras da vida, objetivando alívio do sofrimento seja de sintomas físicos, sociais, psicológicos e espirituais, desde o diagnóstico até o processo de luto, também para os familiares (WHO, 2002).

A abordagem do cuidado paliativo é baseada em alguns princípios como: promover o alívio da dor, considerar a morte um processo natural, não acelerar nem adiar a morte, incorporar aspectos psicológicos e espirituais, fornecer suporte para que o paciente viva ativamente até sua morte, suporte para os familiares durante a doença e o luto, melhorar a qualidade de vida e curso da doença, além de iniciar precocemente todos os tipos de cuidados necessários para o paciente (WHO, 2017).

Haja vista a associação da doença oncológica com a terminalidade da vida e sofrimento, uma forma de assistência humanizada comumente ofertada aos pacientes é o cuidado paliativo. Essa filosofia de cuidado pode ser associada a outras formas de tratamento para a doença, devendo ser iniciada desde o diagnóstico e intensificada conforme a necessidade (Lima \& Oliveira, 2015).

A equipe de saúde deve discutir de forma clara com os pacientes e familiares sobre as formas de cuidado e quais são os seus desejos, valores e preferências (Ngo-Metzger, August, Srinivasan, Liao \& Meyskens, 2008), pois o processo de adoecimento interfere significativamente na vida do indivíduo e, portanto, o cuidado por uma equipe multidisciplinar deve atender de forma integral e singular, todas as necessidades do paciente, propiciando a autonomia, desde o acolhimento da demanda até o processo de luto familiar (Cardoso, Muniz, Schwartz \& Arrieira, 2013).
O profissional da enfermagem é essencial na equipe de cuidados à saúde durante todo o ciclo de vida, envolve ações técnicas e humanitárias. Portanto, na formação dos profissionais de saúde nos cuidados de fim de vida o enfoque no preparo deve ir além da técnica (Whitehead (2012).

A vivência do diagnóstico e tratamento de uma doença ameaçadora da vida como o câncer, acarreta mudanças no meio social do paciente, principalmente no ambiente de trabalho. O abalo físico e emocional é fator negativo para a continuidade no trabalho. Mas, com adequado apoio social, estrutura física do ambiente apropriada, diálogo e autonomia de forma efetiva auxiliam esse processo (Dorland, Abma, Roelen, Smink, Ranchor \& Bültamann, 2016).

As reflexões sobre o cuidado humanizado trazidas por uma profissional de saúde que, em sua prática, vivencia concomitantemente o processo de diagnóstico e tratamento de uma doença ameaçadora da vida foi o objetivo deste estudo.

\section{Metódo}

A pesquisa foi aprovada pelo comitê de ética sob parecer número 3.622.103 e a participante assinou o Termo de Consentimento Livre e Esclarecido (TCLE).

Trata-se de pesquisa qualitativa baseada em um único relato oral. A participante é uma profissional da área de Enfermagem há 28 anos. Teve o diagnóstico de uma doença ameaçadora da vida há três anos e vivencia um processo de tratamento e intervenções até então. A coleta de dados ocorreu entre os meses de junho e outubro de 2019. O relato foi coletado individualmente em uma sala reservada na unidade hospitalar que a profissional atua há 15 anos, tendo sido gravado e, posteriormente, transcrito para análise do conteúdo e discussão com a literatura. A questão norteadora sobre a vivência do processo de morte na atuação profissional, voltada a vários profissionais de saúde para a pesquisa da dissertação, teve um novo enfoque para esta profissional de enfermagem, a qual posicionou-se como sendo uma pessoa que vivencia esse processo em sua vida, não só em sua profissão, desde o momento que soube do diagnóstico.

\section{Resultados}

A análise do conteúdo do relato permitiu reflexões acerca das seguintes categorias: o preparo do profissional de saúde para o cuidado humanizado; a multidimensionalidade do ser humano no processo saúde-doença; a habilidade de comunicação do profissional de saúde e a espiritualidade como fonte de apoio para aceitação da doença. 
O relato oral transcrito está apresentado na íntegra, logo abaixo, com nome fictício.

"Meu nome é Esmeralda e sou enfermeira formada há 28 anos, aqui nessa unidade hospitalar trabalho há 15 anos. Através da minha prática eu vejo que o cuidado em saúde para ser de qualidade, precisa associar a técnica e a humanização, a essência da enfermagem é o cuidar, entendeu? Depois de tanto tempo de experiência eu vejo a mecanização do trabalho, o cuidado às pessoas com doenças ameaçadoras da vida, dentro dos cuidados paliativos você não pode esquecer as prioridades do paciente. Precisamos ter uma preocupação voltada a esse ser, a essa pessoa, a história dele, o jeito dele, o respeito acima de tudo, isso é um desafio, porque estamos numa era extremamente tecnológica e estamos perdendo isso. Nesse processo desses anos você vai adquirindo experiência, posso te garantir que as primeiras situações de óbito, de conversa com a família, de colocar um quadro de prognóstico reservado, são totalmente diferentes de hoje. É muito difícil, talvez um dos processos mais difíceis que você mais encontra na enfermagem, comunicar a família. Tudo isso quando você começa se transferir em situações pessoais, ai você se identifica e você vê o quanto é difícil, tem que ter um suporte de uma equipe multidisciplinar, eu acho essencial em uma instituição ter isso, porque é um momento muito delicado, fragilizado, por mais que você esteja "acostumado", isso faz parte da rotina, mas isso mexe com o emocional do profissional, e isso não é fácil, você lidar diariamente com a dor, com a perda, é um trabalho que é um desgaste muito grande sabe. Eu, uma vez, comuniquei à família que o paciente tinha entrado em óbito por telefone e isso eu sei que eu jamais faria de volta, nunca de forma alguma, porque a pessoa que me atendeu nesse momento desmaiou, teve uma sincope, eu me senti muito mal, muito mal mesmo, e acho que estamos caminhando para melhor forma, se é que existe uma melhor forma de se comunicar. Eu acho que você nunca pode esquecer que você está diante de um ser humano como você, mas que nesse momento você é o profissional, isso é difícil para você ter essa postura, mas é importante amadurecer, as experiências vão te dando suporte. Eu passei recentemente por um diagnóstico de câncer de mama, precisei me afastar do meu trabalho para realizar o tratamento e por isso fui remanejada para a auditoria. Hoje eu estou praticamente curada, fiz uma cirurgia e faço tratamento diariamente, mas para mim foi um baque receber esse diagnóstico, principalmente por ser da área da saúde jamais me imaginei voltar a ser o paciente, passar pelos procedimentos, cirurgias, tudo isso, ai você começa a entender o que é estar lá, dependendo dos cuidados paliativos, do cuidar, do cuidar humanizado. É importante que você não seja vista como uma pessoa fragilizada e incapaz, olhar o paciente como pessoa e não somente como doença, é preciso que a verdade seja exposta sempre, o mais claro possível e com cuidado humanizado. Eu senti isso, é pessoal mesmo, eu precisei ouvir isso e eu sei que tive muitas pessoas que estiveram comigo em seus pensamentos, em suas forças, nas suas orações e eu senti isso nitidamente e sinto até hoje, pessoas que chegaram para mim e falaram: eu não pude estar com você, eu não tive forças para isso, mas eu estive em orações por você, independentemente de ser pastor evangélico, tudo isso é muito importante. A gente precisa muito do apoio da família, dos amigos e de todos os profissionais que te acompanham. Depois de tudo, tanto pessoal quanto profissional, de tudo que eu presenciei do processo de morrer de paciente com prognósticos reservados eu vejo que a morte é uma passagem, eu tenho bem o lado espiritual associado, é difícil para gente cortar essas ligações afetivas com essa pessoa, é física, entendeu? A morte estabelece isso, a transferência é difícil, você encara essa ausência física dessa pessoa no teu meio."

\section{Discussão}

O cuidado em saúde demanda a integralização entre conhecimento técnico e cuidado humanizado, visando sempre atender as necessidades dos pacientes e familiares (Cardoso, Muniz, Schwartz \& Arrieira, 2013) A equipe de saúde e, principalmente, o enfermeiro tem suas práticas permeadas por uma rede de relações, interações, associações e significados no processo de cuidado dos pacientes em todos os ciclos da vida (Backes, Backes, Sousa \& Erdmann, 2008).

De acordo com Esmeralda, o cuidado em saúde demanda da equipe em saúde, tanto o conhecimento técnico quanto uma abordagem de cuidados humanizados.

"[...] Precisa associar a técnica e a humanização, a essência da enfermagem é o cuidar [...] Depois de tanto tempo de experiência eu vejo a mecanização do trabalho [...] precisamos ter uma preocupação voltada a esse ser, a essa pessoa, a história dele, o jeito dele, o respeito acima de tudo, isso é um desafio, porque estamos numa era extremamente tecnológica e estamos perdendo isso".

Em consonância com o relato acima Backes, Backes, Sousa \& Erdmann, 2008, expõem a importância dos profissionais da enfermagem refletirem sobre suas atuações, 
para que essas não sejam realizadas de forma mecanizada, sem olhar as subjetividades implicadas no processo de cuidar. Com o aumento dos recursos tecnológicos em saúde muitos profissionais acabam esquecendo da importância das relações humanas ao se cuidar de pessoas (Lima, Jesus \& Silva, 2018). Torna-se imprescindível, para além da ciência, focalizar as ações pela qualidade de vida e dignidade humana, por meio de ações humanizadas (Alves, Cunha, Santos \& Melo, 2019).

A Política Nacional de Humanização (PNH) e a Política Nacional de Humanização da Assistência Hospitalar (PNHAH) tem como intuito a coparticipação de todos os atores envolvidos no processo de saúde, como usuário, trabalhador e gestor, a fim de proporcionar tratamentos de saúde de forma mais efetiva, respeitando a autonomia e protagonismo e práticas em saúde mais humanitárias (Brasil, 2010).

Vivenciar o diagnóstico e o enfrentamento de uma doença ameaçadora da vida é um processo singular de cada indivíduo, trazendo reflexões acerca de sua existência e mudanças na rotina de vida (Santos \& Sales, 2011).

A etapa da descoberta da doença e as mudanças decorrentes são momentos vividos com sofrimento por Esmeralda.

"Eu passei recentemente por um diagnóstico de câncer de mama e precisei me afastar do meu trabalho para realizar o tratamento [...], principalmente por ser da área da saúde jamais me imaginei voltar a ser o paciente, passar pelos procedimentos, cirurgias, tudo isso, ai você começa a entender o que que é estar lá, dependendo dos cuidados paliativos, do cuidar, do cuidar humanizado".

Comumente, o processo de adoecimento vem acompanhado de sofrimento intenso ao paciente e seus familiares, diante da incerteza de seu prognóstico, medo da morte e afastamento de seus entes queridos, dentre vários outros sentimentos. O diagnóstico de uma doença oncológica remete diretamente a fase de finitude e os estigmas socialmente construídos a partir da doença, fatores esses que impactam intensamente a vida do paciente e seus familiares (Dossena \& Zacharias, 2017). No relato de Esmeralda foi possível verificar o impacto do diagnóstico da doença em várias dimensões de sua vida, ocasionando mudanças na rotina diária e profissional, diante da demanda para o tratamento.

Segundo Schiavon, Muniz, Azevedo, Cardoso, Matos e Arrieira (2016), ser profissional de saúde e conviver com doenças ameaçadoras da vida no eixo familiar contri- buem na tomada de decisões terapêuticas, porém também causam grande sofrimento. O profissional, por conhecer sobre os prognósticos e a assistência em saúde, pode se sentir preocupado ao enfrentar o diagnóstico de uma doença ameaçadora da vida. Vivenciar essa experiência pessoal do diagnóstico e tratamento de uma doença ameaçadora da vida e depender dos serviços de saúde como paciente fez com que Esmeralda repensasse suas práticas.

"[...] quando você começa se transferir em situações pessoais, ai você se identifica e você vê o quanto é difícil, tem que ter um suporte de uma equipe multidisciplinar eu acho essencial em uma instituição ter isso, porque é um momento muito delicado".

A equipe multidisciplinar citada por Esmeralda é essencial para o trabalho efetivo em cuidados humanizados, a fim de atender a multidimensionalidade dos seres humanos e, para isso, é necessária a troca de conhecimento e corresponsabilidades com o objetivo de atender em conjunto as necessidades dos pacientes e familiares (Cardoso, Muniz, Schwartz \& Arrieira, 2013; Hermes \& Lamarca, 2013).

As experiências pessoais de Esmeralda com o adoecimento revelam a percepção de como os pacientes gostariam de ser atendidos.

"É importante que você não seja vista como uma pessoa fragilizada e incapaz, tem que olhar o paciente como pessoa e não somente como doença".

O cuidado integral no processo saúde-doença deve ser ofertado conforme as necessidades individuais, focando no acolhimento e clínica ampliada através de um olhar holístico, sempre colocando o paciente como protagonista e respeitando sua autonomia. Essa forma de entender o processo saúde-doença vem sofrendo mudanças com o tempo, sentindo a necessidade de se olhar a multidimensionalidade envolvida nesse processo e não apenas a patologia. Porém, ainda se observa a dificuldade encontrada pelos profissionais de saúde em estabelecer relações para além da técnica (Pedrosa \& Polejack, 2016).

Outro aspecto importante durante o enfrentamento da doença é a comunicação efetiva entre os profissionais de saúde, pacientes e familiares com base nos seguintes aspectos: honestidade, humanização e escuta qualificada, deixando transparente as reais possibilidades terapêuticas, porém, sempre com sensibilidade (Moritz, 2007). Esmeralda recorda sobre suas práticas profissionais, quando ela era a intermediadora da comunicação. 
"Eu uma vez. comuniquei à familia que o paciente tinha entrado em óbito por telefone e isso en sei que eu jamais faria de volta".

É possível evidenciar no relato, o que sensibilizou Esmeralda com relação à falta de acolhimento e cuidado com a comunicação aos familiares na sua prática, a partir da sua experiência profissional e vivência com uma doença ameaçadora da vida.

"[...] posso te garantir que as primeiras situacõos de óbito, de conversa com a família, de coloca um quadro de prognostico reservado são totalmente diferentes de hoje".

Essas notícias quando não realizadas de forma efetiva causam grande impacto na vida dos envolvidos, pois nesse momento, é preciso que prevaleça o acolhimento e a escuta das necessidades, valorizando a autonomia no processo terapêutico (Andrade, Costa \& Lopes, 2013).

Segundo Fernandes, Evangelista, Platel, Agra, Lopes e Rodrigues (2013), a comunicação verbal e não verbal, prestada de forma adequada, favorece a promoção do cuidado efetivo e alivio dos sintomas emocionais, como medos e inseguranças que acompanham a fase do adoecimento. Esmeralda relata sua experiência pessoal e profissional na defesa de uma comunicação clara e transparente sobre as reais condições de saúde, a fim de promover a autonomia e a participação efetiva do paciente no processo terapêutico.

Araújo (2011) relata em seu estudo sobre as habilidades de comunicação interpessoal e a dificuldade dos profissionais em comunicar notícias difíceis, como em casos de doenças ameaçadoras da vida e morte, pois a base de suas formações foram voltadas para salvar vidas e quando a possibilidade de cura já não é mais possível muitos profissionais sentem-se frustrados e apresentam dificuldades com relação a um comunicação assertiva e compassiva. Esmeralda relata sobre a dificuldade em lidar com esses momentos.

"[...] é um momento muito delicado, fragilizado, por mais que você esteja "acostumado", isso faz parte da rotina, mas isso mexe com o emocional do profissional, e isso não é fácil, você lidar diariamente com a dor, com a perda, é um trabalho assim que é um desgaste muito grande sabe".

A expressão "acostumado" pode ser interpretada como algo comumente enfrentado na rotina profissional e Alves, Cunha, Santos \& Melo (2019) ressaltam o quanto uma discussão ampliada nas formações e capacitações dos profissionais de saúde sobre o cuidado humanizado no processo de morte, incluindo o cuidado paliativo, é primordial, a fim de que o profissional saiba lidar da forma mais adequada na oferta dos cuidados adequados aos pacientes e familiares e não sofrer interferências prejudiciais ao seu emocional.

"[...] acho que estamos caminhando pra melhor forma, se é que existe uma melhor forma de se comunicar, eu acho que você nunca pode esquecer que você está diante de um ser bumano como você, mas que nesse momento você é o profissional, isso é difícil pra você ter essa postura, mas é importante amadurecer, as experiências vão te dando suporte".

Uma assistência humanizada para pessoas com doenças ameaçadoras da vida, visa proporcionar conforto e prevenção de agravos, ofertar apoio emocional e social ao paciente e familiares (Othero, 2010), pois neste momento da finitude, surge a necessidade de receber apoio da equipe de saúde e também apoio espiritual para auxiliar no enfrentamento desse processo e na busca de significados para o adoecimento.

"[...] A gente precisa muito do apoio da família, dos amigos e de todos os profissionais que te acompanham".

A espiritualidade é uma forma de enfrentamento que os pacientes diante da iminência da morte têm como apoio para amenizar seus medos, na busca de significados para a vida e a morte (Gomes, Xavier, Carvalho, Cordeiro, Ferreira \& Morbeck, 2019). Para Esmeralda, este apoio foi singular no processo de aceitação da doença

"[...] as pessoas falavam eu estive em orações por você, independentemente de ser pastor evangélico, tudo isso é muito importante".

O relato de Esmeralda revela a transparência da sensibilidade necessária para o cuidado prestado pelos profissionais de saúde, envolvendo todos os aspectos sejam eles físicos, emocionais, sociais e espirituais, que garantam a oferta de maior qualidade de vida aos envolvidos em um processo permeado de sofrimento e dor, através de práticas humanizadas que propiciem o conforto físico e espiritual.

\section{Conclusão}

O relato de Esmeralda desperta a necessidade de mudança de paradigma sobre as práticas profissionais, a partir de um olhar mais humanizado frente ao processo 
de morte e morrer. Vivenciar o diagnóstico e o tratamento de uma doença ameaçadora da vida, enquanto profissional do cuidado em saúde em ambiente hospitalar, permitiu o ensaio de reflexões sobre o preparo do profissional de saúde para um cuidado humanizado, com foco na multidimensionalidade do ser humano no processo saúde-doença. A habilidade de comunicação do profissional com o paciente e familiares que vivenciam a finitude tem relevância enquanto ferramenta imprescindível para uma prática humanizada do cuidado. A espiritualidade aparece como fonte de apoio para aceitação da doença.

A subjetividade presente em um relato único e singular pode não traduzir o ideal de um grupo de profissionais com relação à humanização do cuidado, sendo que isto pode ser considerado uma limitação do estudo, mas permitiu trazer evidências das fragilidades e das conquistas de uma profissional de saúde com doença ameaçadora da vida e que cuida de pessoas no processo de morte.

\section{Referências}

Alves, R.S.F.; Cunha, E.C.N.; Santos, G.C. \& Melo, M.O. (2019). Cuidados Paliativos: Alternativa para o Cuidado Essencial no Fim da Vida. Psicologia: Ciência e Profissão. v. 39, e185734, 1-15.

Andrade, C.G; Costa, S.F.G \& Lopes, M.E.L. (2013). Cuidados paliativos: a comunicação como estratégia de cuidado para o paciente em fase terminal. Ciência \& Saúde Coletiva, 18(9):2523-2530.

Araújo, M.M.T. (2011). Comunicação em cuidados paliativos: proposta educacional para profissionais da saúde. Tese (Doutorado). Escola de Enfermagem da Universidade de São Paulo. São Paulo.

Azevedo, D; Tommaso, A.B.G; Burlá, C; Santos, G; Dias, L.M; Py, \& Rebello, M. (2015). Vamos falar de Cuidados Paliativos. Sociedade Brasileira de Geriatria e Gerontologia.

Backes, D.S; Backes, M.S; Sousa, F.G.M. \& Erdmann, A.L. (2008). O papel do enfermeiro no contexto hospitalar: a visão dos profissionais de saúde. Cienc Cuid Saúde. Jul/Set; 7(3):319-326.

Brasil (2010). Ministério da Saúde. Política Nacional de Humanização. Série B. Textos Básicos de Saúde, cadernos humaniza SUS.

Cardoso, D.H.; Muniz, R.M.; Schwartz, E. \& Arrieira ICO. (2013). Cuidados paliativos na assistência hospitalar: a vivência de uma equipe multiprofissional. Texto Contexto Enferm, Florianópolis, Out-Dez; 22(4): 1134-41.

Dossena, D.T. \& Zacharias, D.G. (2017). Impacto do diagnóstico oncológico no meio familiar: o papel da Psico-Oncologia. VI Jornada de Pesquisa em Psicologia - PSI UNISC: Pesquisa e Tecnologia na Psicologia Atual.

Dorland, H.F.; Abma, F.I.; Roelen, C.A.M.; Smink, J.G.; Ranchor, A.V. \& Bültmann, U. (2016). Factors influencing work functioning after cancer diagnosis: a focus group study with cancer survivors and occupational health professionals. Support Care Cancer 24:261-266.

Fernandes, M.A; Evangelista, C.B; Platel, I.C.S; Agra, G; Lopes, M.S.; \& Ro- drigues, F. A. (2013). Percepção dos enfermeiros sobre o significado dos cuidados paliativos em pacientes com câncer terminal. Ciência \& Saúde Coletiva, 18(9), 2589-2596.

Gomes, M.V.; Xavier A.S.G.; Carvalho, E.S.S.; Cordeiro, R.C., Ferreira, S.L. \& Morbeck, A.D. (2019). "Waiting for a miracle": Spirituality/Religiosity in coping with sickle cell disease. Rev Bras Enferm. 72 (6):1554-61.

Hermes, H.R. \& Lamarca, I.C.A. (2013). Cuidados paliativos: uma abordagem a partir das categorias profissionais de saúde. Ciência \& Saúde Coletiva, 18(9):2577-2588.

Lima, M.P.O \& Oliveira, M.C.X. (2015). Significados do cuidado de enfermagem para familiares de pacientes em tratamento paliativo. Rev Rene [Internet].16(4):593-602. DOI: 10.15253/2175-6783.2015000400017.

Lima, A.A.; Jesus, D.S \& Silva, T.L. (2018). Densidade tecnológica e o cuidado humanizado em enfermagem: a realidade de dois serviços de saúde. Physis: Revista de Saúde Coletiva, Rio de Janeiro, v. 28(3), e280320.

Moritz, R.D. (2007). Como melhorar a comunicação e prevenir conflitos nas situações de terminalidade na Unidade de Terapia Intensiva. Rev. bras. ter. intensiva, São Paulo, v. 19, n. 4, p. 485-489, Dec. DOI: 10.1590/S0103-507X2007000400014.

Ngo-Metzger, Q.; August, K.J., Srinivasan, M.; Liao, S. \& Meyskens, F.L. Jr. (2008) End-of-Life care: guidelines for patient-centered communication. Am Fam Pbysician. 77(2):167-174.

Othero, M.B. (2010). Terapia Ocupacional na Assistência Oncológica em Geriatria e Gerontologia - Experiências em Cuidados Paliativos no setor privado, Hospital Premier, São Paulo-SP. In (Org.) Terapia Ocupacional: Práticas em Oncologia. São Paulo: Editora Roca. p.388-407.

Pedrosa, N.T \& Polejack, L. (2016) Cuidado e autocuidado em oncologia: significados para profissionais e usuários. Mudanças - Psicologia da Saúde, 24 (2), jul. Dez.

Santos, E.M \& Sales, C.A. (2011). Familiares enlutados: compreensão fenomenológica existencial de suas vivências. Texto Contexto Enferm. 20(Esp):21422. Doi: /10.1590/S0104-07072011000500027.

Sanches, K.S., Rabin, E.G. \& Teixeira, P.T.O. (2018). Cenário da publicação científica dos últimos 5 anos sobre cuidados paliativos em oncologia: revisão de escopo. Rev. esc. enferm. USP, São Paulo, v. 52, e03336.

Schiavon, A.B., Muniz, R.M.; Azevedo, N.A.; Cardoso, D.H.; Matos, M.R. \& Arrieira, I.C.O. (2016). Profissional da saúde frente a situação de ter um familiar em cuidados paliativos por câncer. Rev. Gaúcha Enferm. mar;37(1):e55080. Doi: 10.1590/1983-1447.2016.01.55080.

Whitehead, P.R. (2012). The lived experience of physicians dealing with patient death. BMJ Supportive \& Palliative Care. 4:271-276.

WHO - WORLD HEALTH ORGANIZATION (2002). National cancer control programmes: policies and managerial guidelines. 2.ed. Geneva: WHO. Disponível em: https://apps.who.int/iris/bitstream/handle $/ 10665 / 37815 / 9241544740$. pdf? sequence $=1$ \&isAllowed $=y$

WHO - WORLD HEALTH ORGANIZATION (2017). Definition of Palliative Care. Disponível em http://www. who.int/cancer/palliative/definition/en/. [acesso em outubro 2017].

Submetido em: 20-2-2020

Aceito em: 17-8-2020 